\title{
Characterizing regional precipitation-driven lake area change in Mongolia
}

\author{
Sinkyu KANG ${ }^{1 *}$, Gyoungbin LEE ${ }^{1}$, Chuluun TOGTOKH², Keunchang JANG ${ }^{1}$ \\ ${ }^{1}$ Department of Environmental Science, Kangwon National University, Chuncheon 200-701, South Korea; \\ ${ }^{2}$ Institute for Sustainable Development, National University of Mongolia, Ulaanbaatar 14201, Mongolia
}

\begin{abstract}
Lake area is an important indicator for climate change and its relationship with climatic factors is critical for understanding the mechanisms that control lake level changes. In this study, lake area changes and their relations to precipitation were investigated using multi-temporal Landsat Thermatic Mapper (TM) and Enhanced Thermatic Mapper plus (ETM+) images collected from 10 different regions of Mongolia since the late 1980s. A linear-regression analysis was applied to examine the relationship between precipitation and lake area change for each region and across different regions of Mongolia. The relationships were interpreted in terms of regional climate regime and hydromorphological characteristics. A total of 165 lakes with areas greater than $10 \mathrm{hm}^{2}$ were identified from the Landsat images, which were aggregated for each region to estimate the regional lake area. Temporal lake area variability was larger in the Gobi regions, where small lakes are densely distributed. The regression analyses indicated that the regional patterns of precipitation-driven lake area changes varied considerably $\left(R^{2}=0.028-0.950\right)$, depending on regional climate regime and hydromorphological characteristics. Generally, the lake area change in the hot-and-dry Gobi regions showed higher correlations with precipitation change. The precedent two-month precipitation was the best determining factor of lake area change across Mongolia. Our results indicate the usefulness of regression analysis based on satellite-derived multi-temporal lake area data to identify regions where factors other than precipitation might play important roles in determining lake area change.
\end{abstract}

Keywords: lake area; climate; hydromorphology; Landsat image; regression analysis

Citation: Sinkyu KANG, Gyoungbin LEE, Chuluun TOGTOKH, Keunchang JANG. 2015. Characterizing regional precipitation-driven lake area change in Mongolia. Journal of Arid Land, 7(2): 146-158. doi: 10.1007/s40333-014-0081-x

Arid and semi-arid regions of Mongolia, which comprise $90 \%$ of the national land, are endangered due to land degradation, according to the FAO/UNEP guideline for desertification (UNEP RRC.AP, 2002). Over the last several decades, a vast amount of land degradation has occurred, especially in Mongolian grasslands, which might be related to changes in the regional climate and socio-economic conditions (Neupert, 1996; Dietz et al., 2005; Johnson et al., 2006). Along with reported temperature increases of $1.6^{\circ} \mathrm{C}$ since the 1960s (Batima et al., 2005), the annual precipitation substantially decreased during the 2000s, which could alter the regional water balance of grassland ecosystems and reduce the available water resources in Mongolia. Overall, Mongolia possesses plenty of inland water resources, but huge numbers of rivers $(702)$, lakes $(4,196)$ and wells $(1,484)$ disappeared or were depleted between the late 1990s and early 2000s (Davaa et al., 2006), aggravating the exacerbation of desertification and the deterioration of local socio- economic systems. Among the various water-resource components, lake water is the largest one (approximately $500 \mathrm{~km}^{3}$ ), providing more than $80 \%$ of the total freshwater resources $\left(599 \mathrm{~km}^{3}\right)$ in Mongolia (Davaa et al., 2006). Because of the dominant role of lake water for local water demands, monitoring and understanding the temporal variation of lake water is important for water-resource management and relevant

*Corresponding author: Sinkyu KANG (E-mail: kangsk@kangwon.ac.kr)

Received 2014-02-10; revised 2014-05-12; accepted 2014-06-03

(C) Xinjiang Institute of Ecology and Geography, Chinese Academy of Sciences, Science Press and Springer-Verlag Berlin Heidelberg 2015 
socio-economic activities in the dryland areas. Because lake water levels are directly linked with nearby ground-water depth, lake area might be a useful indirect indicator of basin-scale ground-water variation. Hence, regional monitoring of lake area and its relation to precipitation changes can provide important information on both local and regional water availability under a changing climate across various regions in Mongolia.

There have been several studies of temporal variations of the water resources in Mongolia. Komatsu et al. (2001) used RADARSAT SAR images to investigate Orog Lake in southern Mongolia. Tsujimura et al. (2007) conducted field surveys on ground-water quality in areas of the Kherlen River basin located in the eastern semi-arid region of Mongolia. Nadintsetseg and Shinoda (2011) analyzed inter-annual variations of soil water content from 26 sites in Mongolia. Davaa et al. $(2005,2006)$ reported changes of water resources in Mongolia based on field-monitoring data. The previous studies focused on understanding the status and changes of water resources based on region-scale field survey data or satellite image data for a specific lake area. The land of Mongolia is large and contains considerable spatial variability in climate, vegetation and water resources. Accordingly, the status and dynamics of lake-water resources need to be investigated across the diverse climate regimes to identify the major drivers of the changes.

Multi-temporal satellite remote-sensing images are useful datasets to monitor changes of lake-water resources across the diverse regions of Mongolia. Landsat images were used to investigate the dynamic changes of playa lakes in the Monegros Desert in Spain (Castaneda et al., 2005). Various satellite data from Landsat, ASTER, MODIS, NOAA AVHRR and JERS-1 were applied to analyze long-term changes of lake surface area in Central Asia (Nakayama et al., 2007). Haijiang et al. (2008) used Landsat images to identify desertification in Inner Mongolia, China. Those studies used multi-temporal satellite images to monitor changes of lake-water resources. The information from multi-temporal satellite images could be further applied to investigate cause-and-effect relations between lake-water resource dynamics and their controlling factors, such as precipitation, temperature and hydromorphological characterisics.

Lake-water dynamics in dry environments are strongly affected by inter-annual or seasonal variations in precipitation (Castaneda et al., 2005). Depending on the region, warming temperature could have either negative or positive effects through enhanced evapotranspiration or increased water supply from glacier or permafrost melts. Anthropogenic water use might have also affected water-resource dynamics in some regions due to high water demands from increased livestock populations and/or mining activities since the start of the free-market era in Mongolia (Johnson et al., 2006; Saizen et al., 2010), both of which can result in reductions of lake surface area with river-level and ground-water drawdown. The warming temperature and anthropogenic water use could have a significant effect on basin-scale hydrological processes associated with lake-water resources in some regions. Given changes in precipitation, temperature and anthropogenic water use, lake water resources can vary differently depending on regional hydromorphological charactersistics such as lake size and distribution (i.e. terminal or riverside lakes), and basin size and topography. To evaluate those various factors and their relations with lake water resources, a broad regional study is necessary to cover enough gradients of climate regime and hydromorphological characteristics.

In this study, we detected lake surface area as a proxy of the amount of lake-water resources using multi-temporal Landsat TM and ETM+ images and examined the temporal changes and relations of lake areas with precipitation across 10 different regions in Mongolia. Temporal correspondence between lake area and precipitation change was examined for several selected study regions. Occurrence of cross- regional correspondence was also explored across the whole study area. The region-specific and cross- regional correspondences between lake area and precipitation change were interpreted in terms of regional climate regime and hydromorphological characteristics.

\section{Materials and methods}

\subsection{Study area}

Mongolia is an inland country with a land area of $1.56 \times 10^{6} \mathrm{~km}^{2}$ and a mean elevation of $1,580 \mathrm{~m}$. Desert and arid and semi-arid grasslands compose $80 \%$ 
of the land area. The west of the country generally has a higher elevation than the east (Fig. 1). The major mountain regions are the Altai, Hanggai and Henti ranges in the west, mid-west and mid-northeast, respectively. The ranges are important natural water reserves that provide stream and ground water to arid lowlands. The north has vegetated permafrost land with a transition from northern boreal forest to southern grassland biomes. The south has dry Gobi area with sparse vegetation cover and an annual precipitation of around or below $200 \mathrm{~mm}$. The middle has vast grasslands with tall and short grasses from the north to the south. The east has lowlands, with elevations of below $1,000 \mathrm{~m}$, a less arid climate and tall grasslands. The highest mountain ranges, with elevations of over $4,000 \mathrm{~m}$, are located near the western border with China. The mountain ranges supply plenty of water to constitute large lakes in the northwest and north, while small lakes are more abundant in the other regions.

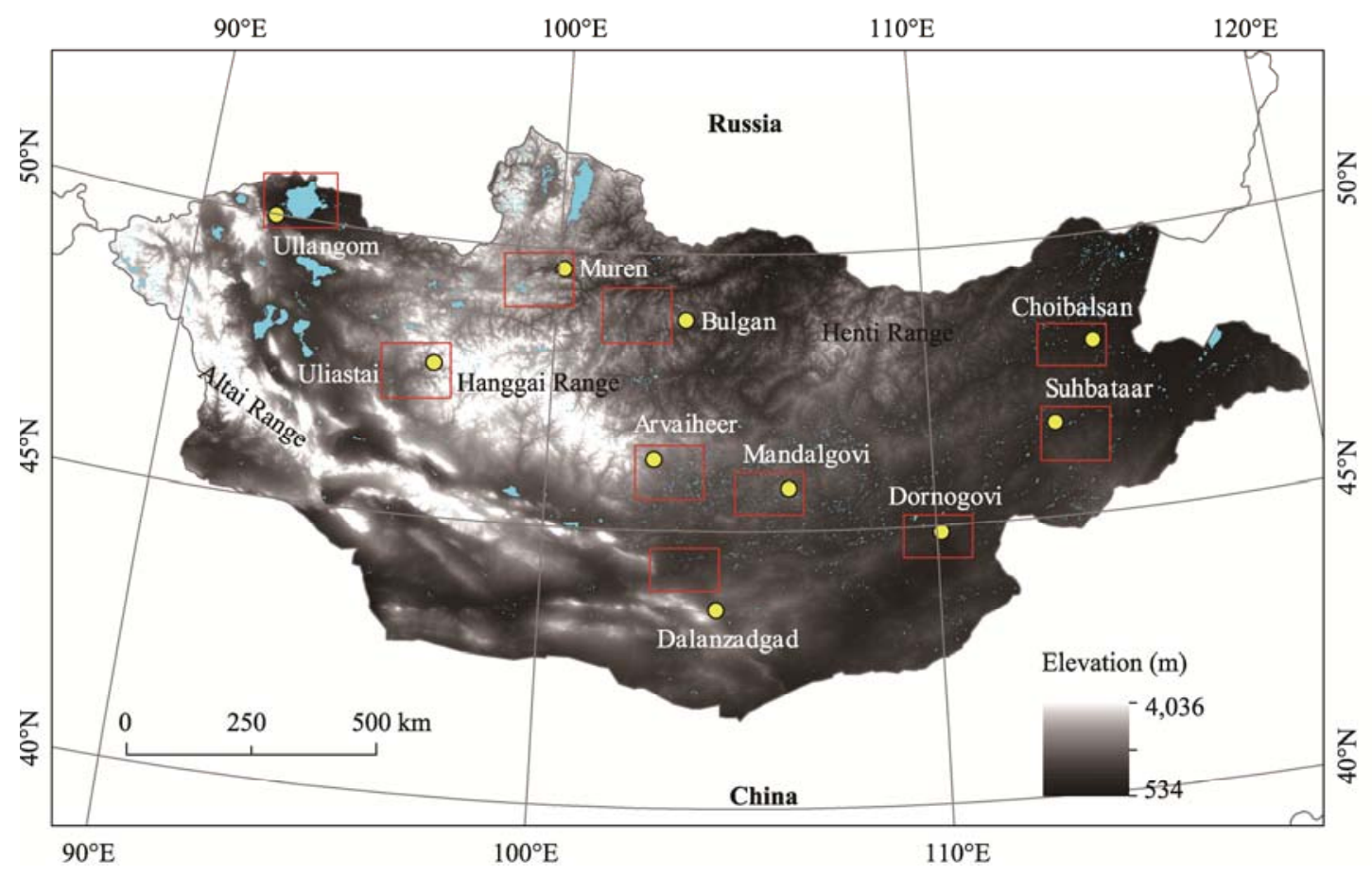

Fig. 1 Geographical illustrations on topography and lake distribution in Mongolia. Approximate locations of three major mountain ranges were given with the range names. Locations of the weather stations used in this study were marked as closed circles with the name of cities. Small rectangles indicate Landsat sub-image coverages used in this study. The background map is $1 \mathrm{~km}$ resolution DEM from USGS Hydro1k database. Lake polygon GIS layer from Ministry of Environment and Green Development of Mongolia was overlaid on the DEM map.

Mongolia has plenty of inland water resources. The number of lakes is over 3,000, but these lakes are unevenly distributed, with a few large lakes in the northwest and many small lakes in the east (Fig. 1). The south (i.e. the Gobi area) has a few highly scattered small lakes. Many of the scattered lakes in the Gobi have suffered from water depletion and temporary disappearance for the last several decades (Chuluun et al., 2010; Yang et al., 2012). We selected 10 regions across Mongolia depending on the data availability of multi-temporal Landsat images (Fig. 1).

\subsection{Data collection}

Monthly mean air temperatures and monthly total precipitation data were collected from 10 national weather stations in Mongolia (Fig. 1). The collected data span up to 60 years and represent diverse biome types and climatic regimes in Mongolia. Because our concern was primarily to investigate the effect of precipitation on lake area change, we confined our study areas to regions containing the north, west and south (NWS, except for the Dalanzadgad region in the 
south). The collected NWS data indicate that temperature has risen, especially since the late 1980s, but that precipitation has generally decreased since the early 1990s, although there have been considerable interannual precipitation fluctuations.

Landsat TM and ETM+ images were collected for each NWS location. The Landsat images were used to detect the lake surface area at $30 \mathrm{~m}$ resolution. At least two multi-temporal images with overlapping scanning areas were therefore necessary to determine changes in lake surface area. The images used in this study were provided by the U.S. Geological Survey. We collected only non-winter images to eliminate the effects of snow and ice cover on the measurements of lake surface area. We also tried for each region to obtain acquisition dates from similar months or seasons to reduce the effect of precipitation seasonality. The collected images were then screened again with a criterion for the cloud fraction, i.e. less than $1 \%$ cloud cover. The rigorous cloud cover screening is applied because we estimated the total area surface of lakes widely distributed in the Landsat image. Consequently, 34 Landsat images in total were selected from 2 to 5 multi-temporal images for each NWS location (Table 1).

For each of the regions, the multi-temporal images were overlaid to select a common sub-image area that was not contaminated by cloud cover. Pixel clusters of cloud cover were identified by visual inspection using a false-color RGB composite image with a combination of 5, 4 and 3 Landsat bands. Before subtracting the sub-images, we conducted image-to-image geometric correction for the TM image using the geometrically corrected ETM+ image for each region. Size of the sub-image was different for each study region depending on overlapping area without cloud contamination. Atmospheric correction was not applied in this study because of practical problems. It was difficult to find dark objects in most of the images for empirical atmospheric correction (Chavez, 1996) and challenging to obtain sufficient atmospheric-profile information for model-based correction. This issue might be less problematic in our study, however, because atmospheric correction has little impact on single image-based classification errors when the sky is clear and homogeneous (Kawata et al., 1990; Song et al., 2001).

Table 1 Total surface area and number for the selected lakes from each Landsat TM and ETM+ image in each region

\begin{tabular}{|c|c|c|c|c|c|c|c|}
\hline Region & Date (dd-mm-yy) & Surface area $\left(\mathrm{km}^{2}\right)$ & No. & Region & Date (dd-mm-yy) & Surface area $\left(\mathrm{km}^{2}\right)$ & No. \\
\hline \multirow{2}{*}{$\begin{array}{c}\text { ULI } \\
(9, \pm 5)\end{array}$} & 28-07-1991 & 21.0 & 4 & \multirow{3}{*}{$\begin{array}{c}\text { MAN } \\
(21, \pm 15)\end{array}$} & 13-05-1993 & 2.0 & 10 \\
\hline & 04-09-2002 & 21.1 & 9 & & 09-06-2000 & 5.6 & 16 \\
\hline \multirow{3}{*}{$\begin{array}{c}\text { ULL } \\
(2, \pm 0)\end{array}$} & $15-06-1991$ & $3,533.3$ & 2 & & $15-06-2002$ & 5.2 & 12 \\
\hline & $25-06-1992$ & $3,504.6$ & 2 & \multirow{5}{*}{$\begin{array}{c}\text { DAL } \\
(20, \pm 20)\end{array}$} & 16-06-1991 & 47.1 & 19 \\
\hline & 08-08-2002 & $3,614.1$ & 2 & & $20-09-2000$ & 5.9 & 10 \\
\hline \multirow{2}{*}{$\begin{array}{c}\text { MUR } \\
(7, \pm 2)\end{array}$} & $15-10-1990$ & 209.4 & 7 & & 21-07-2001 & 4.4 & 7 \\
\hline & $19-09-2001$ & 210.7 & 5 & & $24-07-2002$ & 0.0 & 0 \\
\hline \multirow{5}{*}{$\begin{array}{c}\text { BUL } \\
(21, \pm 3)\end{array}$} & 19-08-1989 & 33.8 & 19 & & $12-08-2006$ & 2.8 & 9 \\
\hline & $17-08-1991$ & 38.4 & 20 & \multirow{4}{*}{$\begin{array}{c}\text { DOR } \\
(26, \pm 24)\end{array}$} & 05-10-1995 & 4.4 & 10 \\
\hline & $20-08-2001$ & 36.5 & 20 & & 24-09-2000 & 28.1 & 23 \\
\hline & $10-08-2006$ & 27.3 & 20 & & 07-06-2001 & 2.6 & 10 \\
\hline & $28-07-2007$ & 24.0 & 17 & & $29-08-2002$ & 19.1 & 18 \\
\hline \multirow{5}{*}{$\begin{array}{c}\text { ARV } \\
(20, \pm 12)\end{array}$} & 09-06-1989 & 3.7 & 10 & \multirow{2}{*}{$\begin{array}{c}\text { SHU } \\
(16, \pm 2)\end{array}$} & $15-09-1987$ & 17.6 & 15 \\
\hline & 23-07-1999 & 9.0 & 20 & & 09-06-2001 & 10.7 & 15 \\
\hline & $11-09-2000$ & 5.2 & 13 & \multirow{3}{*}{$\begin{array}{c}\mathrm{CHO} \\
(23, \pm 2)\end{array}$} & 16-07-1994 & 25.3 & 23 \\
\hline & $10-06-2001$ & 3.4 & 11 & & $05-05-2000$ & 15.2 & 23 \\
\hline & $16-08-2002$ & 4.7 & 14 & & 09-06-2001 & 11.1 & 21 \\
\hline
\end{tabular}

Note: The values in parentheses are the total number of lakes over a $10 \mathrm{hm}^{2}$ area and the total number of lakes that disappeared, at least once, during the imaged dates. ULI, Uliastai; ULL, Ullangom; MUR, Muren; BUL, Bulgan; ARV, Arvaiheer; MAN, Mandalgovi; DAL, Dalanzadgad; DOR, Dornogovi; SHU, Shubaatar; CHO, Choibalsan. 


\subsection{Detection of lake surface area from Landsat images}

The sub-images were used to find lakes and estimate the lake surface area. Instead of sophisticated methods of land-cover classification, we used a simple scheme of unsupervised classification to identify lake-water pixels in this study because we could not collect enough pre-recognizable information on lake distribution over all of the study regions. Additionally, the spectral characteristics of lake water were considerably diverse even within a sub-image, which hampered the selection of enough training sites that were statistically meaningful to cover the diverse lake colors.

In this study, an Iterative Self-Organizing Data Analysis (ISODATA) unsupervised classification method was applied with a varying number of classes from 3 to 10. The ISODATA algorithm permits the number of clusters to change from one iteration to the next, by merging, splitting and deleting clusters (Lillesand et al., 2004). ISODATA is based on $\mathrm{K}$-means clustering algorithm that assigns each pixel in the image to the cluster whose arbitrary mean is closest. Because the classification results from 7 to 10 classes showed the best fit with the visually recognizable water surface, we applied 10 classes for the ISODATA unsupervised classification for every Landsat sub- image. With fewer than 7 classes, some of the dark valley areas were classified as water surfaces. The classified images contained a couple of water classes that might correspond to various lake color schemes, such as clean and dark, shallow and turbid, etc. By comparing with visual lake inspection, the water classes were identified and combined as a single water class. In this study, the unsupervised classification process was aided by visual inspection of surface water from a Landsat 4-5-3 RGB composition (Scepan et al., 1999; Castaneda et al., 2005).

After the detection of lake-water pixels, lake pixel clusters with an area over $10 \mathrm{hm}^{2}$ were chosen for the target lakes of this study to investigate multi-temporal lake area change. This criterion of target lake selection was used because seasonal precipitation or springtime snowmelt can have great effects on the temporal dynamics of small lakes, and hence, temporal disappearance and appearance occur dynamically, such as the patterns observed for playa lakes in desert environments (Castaneda et al., 2005). This situation is not appropriate when investigating long-term, or at least multi-annual, lake area change and its relation with precipitation. The other reason for the $10 \mathrm{hm}^{2}$ criterion was that the classification error increases with smaller lake sizes, especially for lake-boundary pixels. Because a $10-\mathrm{hm}^{2}$ lake can contain approximately 110 Landsat pixels, we assumed that such a lake was large enough to alleviate the sub-pixel heterogeneity problem from the lake-boundary pixels.

To select the target lakes, we overlaid multi-temporal lake-water maps produced from Landsat sub-images and then marked every lake with a size of over $10 \mathrm{hm}^{2}$ at least once. This process was also efficient to screen out river surface water. For each marked lake, lake area change was estimated for all of the possible pairs of two multi-temporal images. For example, ULI, ULL and BUL in Table 1 had 2, 3 and 5 multi-temporal images, which produced 1, 3 and 10 pairs of lake area change data for each selected lake, respectively.

\subsection{Statistical analyses}

We conducted a linear-regression analysis to investigate how much precipitation change explains the variability found in the lake area change. For the regions where precipitation had less explanatory power (significance level, $P<0.05$ ), we qualitatively discussed other factors (i.e. temperature, lake and basin hydromorphological characteristics) to explain the lake area change.

For various sets of total precipitation data during different precedent monthly and annual periods, linearregression analyses were conducted to find out the best precipitation dataset showing the highest correlation $\left(R^{2}\right)$ with the lake area change at each region (Eq. 1). The length of the precedent period and slope of the linear regression were recorded for each region. The period length $\left(l_{m}\right.$, in units of either months or years) and slope $\left(\mathrm{S}, \mathrm{km}^{2} / \mathrm{mm}\right)$ were regarded as a characteristic length of ground-water and precipitation interaction (hereafter, called precipitation memory length) and the sensitivity of lake area change to altered precipitation, respectively. We discuss the region-specific $l_{m}$ and $S$ in relation to the local weather and lake morphological characteristics in section 2.2. The correlation between 
precipitation $(\mathrm{P})$ and lake area $(\mathrm{A})$ change was calculated as follows:

$$
A_{\text {lake }}^{j k}=\alpha+S \cdot\left(\sum_{i=0}^{l_{m}} P_{i}\right)^{j k} .
$$

Where the upper subscript, $j k$, is the change between the $j^{\text {th }}$ and $k^{\text {th }}$ images. Hence, $A_{\text {lake }}^{j k}$ and $\left(\sum_{i=0}^{l_{m}} P_{i}\right)^{j k}$ are changes in the sub-image total lake area and in the precedent total precipitation between the $j^{\text {th }}$ and $k^{\text {th }}$ images, respectively. For example, 5 images can produce 10 pairs of two images and hence, 10 data values for $A_{\text {lake }}^{j k}$ and $\left(\sum_{i=0}^{l_{m}} P_{i}\right)^{j k} . P_{i}$ is either the monthly or annual precipitation for the $i^{\text {th }}$ precedent steps (here, $\mathrm{i}=0$ for the current month or year). The term $l_{m}$ is the length of the precedent precipitation period, which varied from 0 to 5 and from 0 to 1 for monthly and yearly scales (i.e. up to 5 previous months and up to the previous year), respectively. The precipitation memory length $\left(l_{m}\right)$ is determined as the $l_{m}$ showing the highest $R^{2} . S$ and $\alpha$ are the slope and intercept coefficients, respectively.

In addition to the region-specific relation, a national-scale relation between the changes in precipitation and lake area was inspected using the data from all regions. A cross-regional regression analysis was designed to test whether a general relation could be found between changes in lake area and precipitation across the diverse climate and topographic regimes in Mongolia. Because the different extent size of the Landsat subset images for each region hampered cross-regional comparisons of lake area change, the sub-image total lake area change $\left(A_{\text {lake }}^{j k}\right)$ was divided by the subset area $\left(A_{s}\right)$ for calculating the specific lake area change $\left(\overline{A_{\text {lake }}^{j k}}, \mathrm{~km}^{2} / \mathrm{km}^{2}\right)$. The $\overline{A_{\text {lake }}^{j k}}$ was then regressed with the precipitation change $\left(\sum_{i=0}^{l_{m}} P_{i}\right)^{j k}$.

In the region-specific regression analyses, we investigated only four regions (ARV, DOR, DAL and BUL) with more than three Landsat images for better statistical tests (Table 1), while data from all regions were included in the cross-regional regression analyses.

\section{Results and discussion}

\subsection{Spatial and temporal variability of tempera- ture and precipitation}

Considerable inter-regional variations of temperature and precipitation were found across the study regions for the period of 1980-2008. For the study regions, annual mean temperature (AMT) and mean annual precipitation (MAP) ranged from $-2.5^{\circ} \mathrm{C}$ to $5.1^{\circ} \mathrm{C}$ and from 110 to $329 \mathrm{~mm}$ with the means of $1.1^{\circ} \mathrm{C}$ and $203 \mathrm{~mm}$, respectively (Fig. 2a). The lower latitude regions showed a good negative correlation between AMT and MAP $(R=-0.87, P<0.05)$ from DAL to SUB, while the relationship was unclear for the higher- latitude regions. The Gobi regions (i.e. ARV, MAN, DAL and DOR) were distinctly hotter $\left(3.3 \pm 1.7^{\circ} \mathrm{C}\right)$ and drier $(150 \pm 53 \mathrm{~mm})$ than the other regions $\left(-0.5 \pm 1.5^{\circ} \mathrm{C}\right.$ and $240 \pm 60 \mathrm{~mm} ; P<0.05)$.
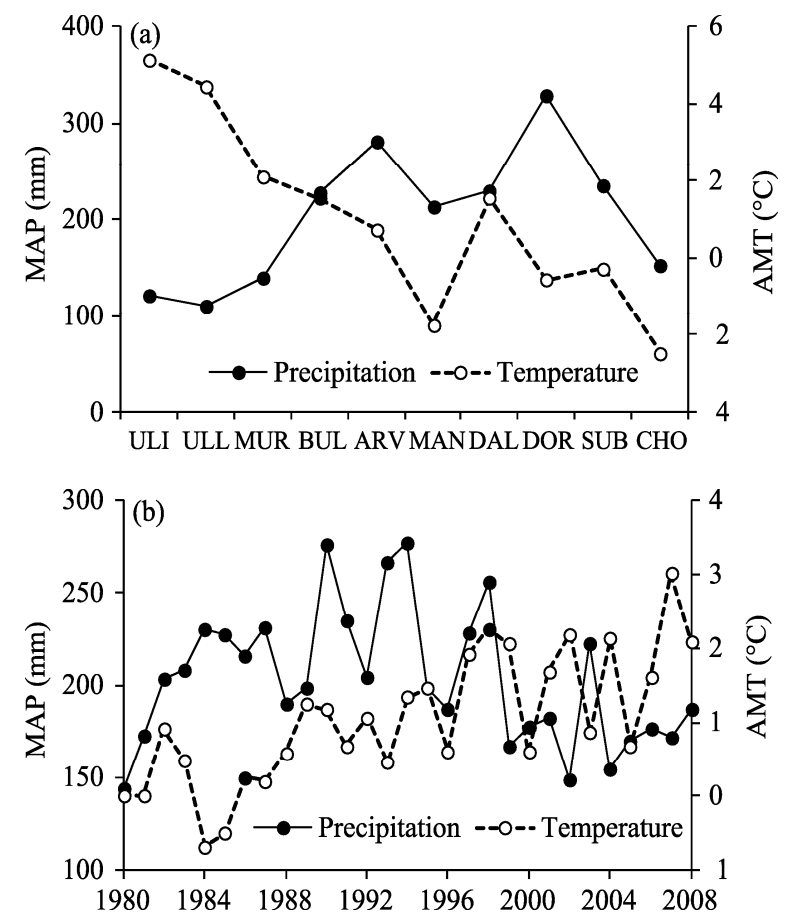

Fig. 2 Spatial and temporal variations of climatic variables: (a) mean annual precipitation (MAP, $\mathrm{mm}$ ) and annual mean temperature (AMT, ${ }^{\circ} \mathrm{C}$ ) of each study region averaged for the period of 1980-2008 and (b) inter-annual variations of MAP and AMT averaged for all study regions from 1980 to 2008. In (a), the study regions were arranged by latitude.

Air temperature gradually increased (slope $=0.078^{\circ} \mathrm{C} / \mathrm{a}$, $P<0.001$ ) with considerable inter-annual fluctuation (Fig. 
$2 b)$. The observed warming trend was higher than that $\left(0.055^{\circ} \mathrm{C} / \mathrm{a}\right)$ from 1940 to 2001 (Batima et al., 2005). For all study regions, the rate of temperature warming ranged from $0.061{ }^{\circ} \mathrm{C} / \mathrm{a}$ to $0.950^{\circ} \mathrm{C} / \mathrm{a}(P<0.001)$. The highest warming rate was found in ULL and MUR, while CHO showed the lowest rate. In contrast, precipitation fluctuated inter-annually with long-term dry and wet spells. There was a wet period during 1990s (MAP $=237 \pm 34$ $\mathrm{mm}$ ), which was followed by a dry period in 2000s $(176 \pm 20 \mathrm{~mm})$. When combining the reported time-series of annual precipitation by Batima et al. (2005) with this study, those wet and dry periods occurred alternatively at decadal scales since 1940.
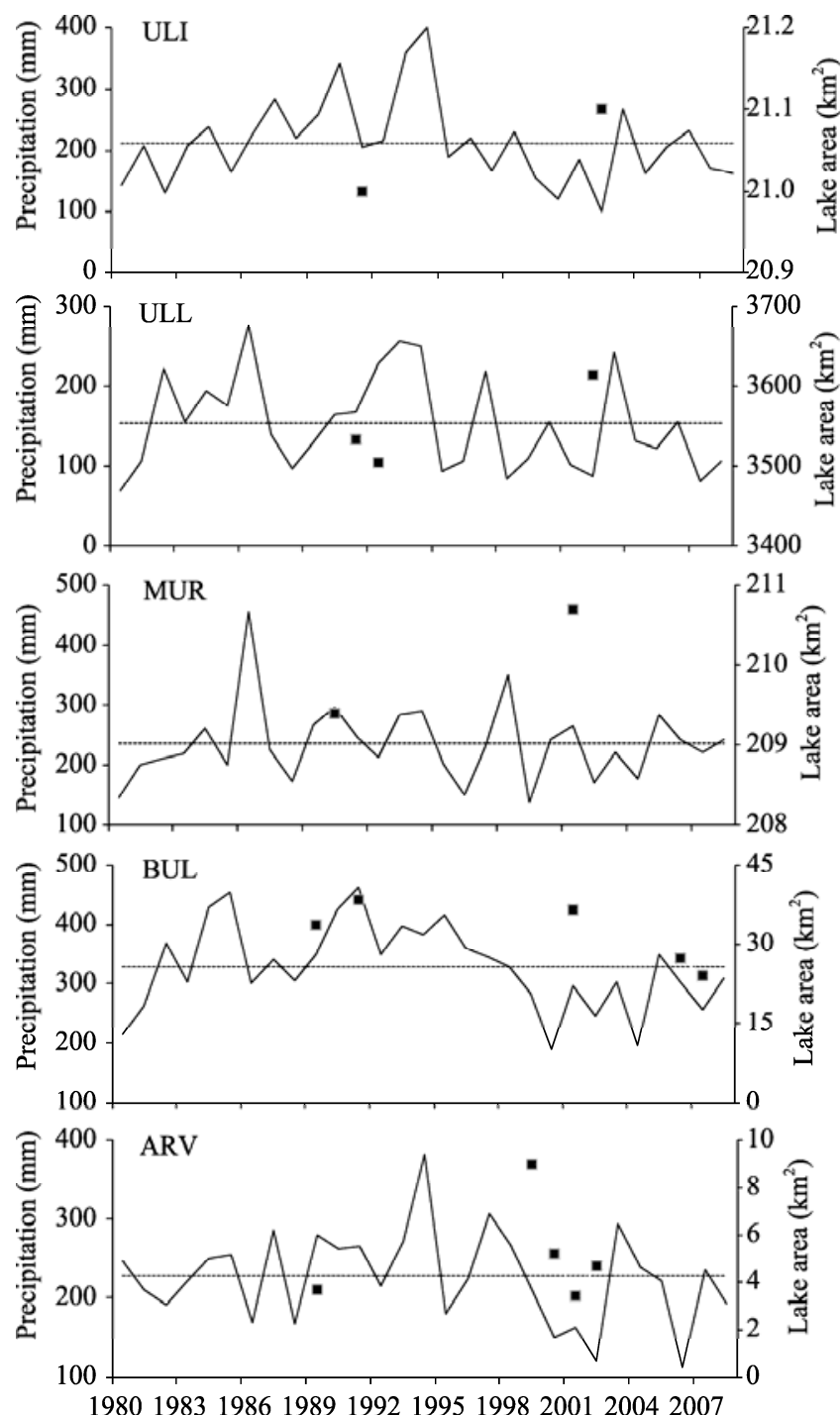

Regional inter-annual variations of precipitation were given in Fig. 3. A higher relative annual variability of precipitation was observed in the dry regions. The temporal precipitation variability (i.e. CV) decreased with the mean annual precipitation across the regions $(R=-0.70, P<0.01)$. Higher inter-annual variability (regional mean $\mathrm{CV}=35.5 \%$ ) was found at the regions with mean annual precipitation of below 200 $\mathrm{mm}$, and that for the other regions was $28.8 \%$. CHO was a peculiar region, showing the largest standard deviation $(\sigma=92 \mathrm{~mm} / \mathrm{a})$ and coefficient of variation $(\mathrm{CV}=40 \%)$ with an intermediate level of precipitation (229 mm).
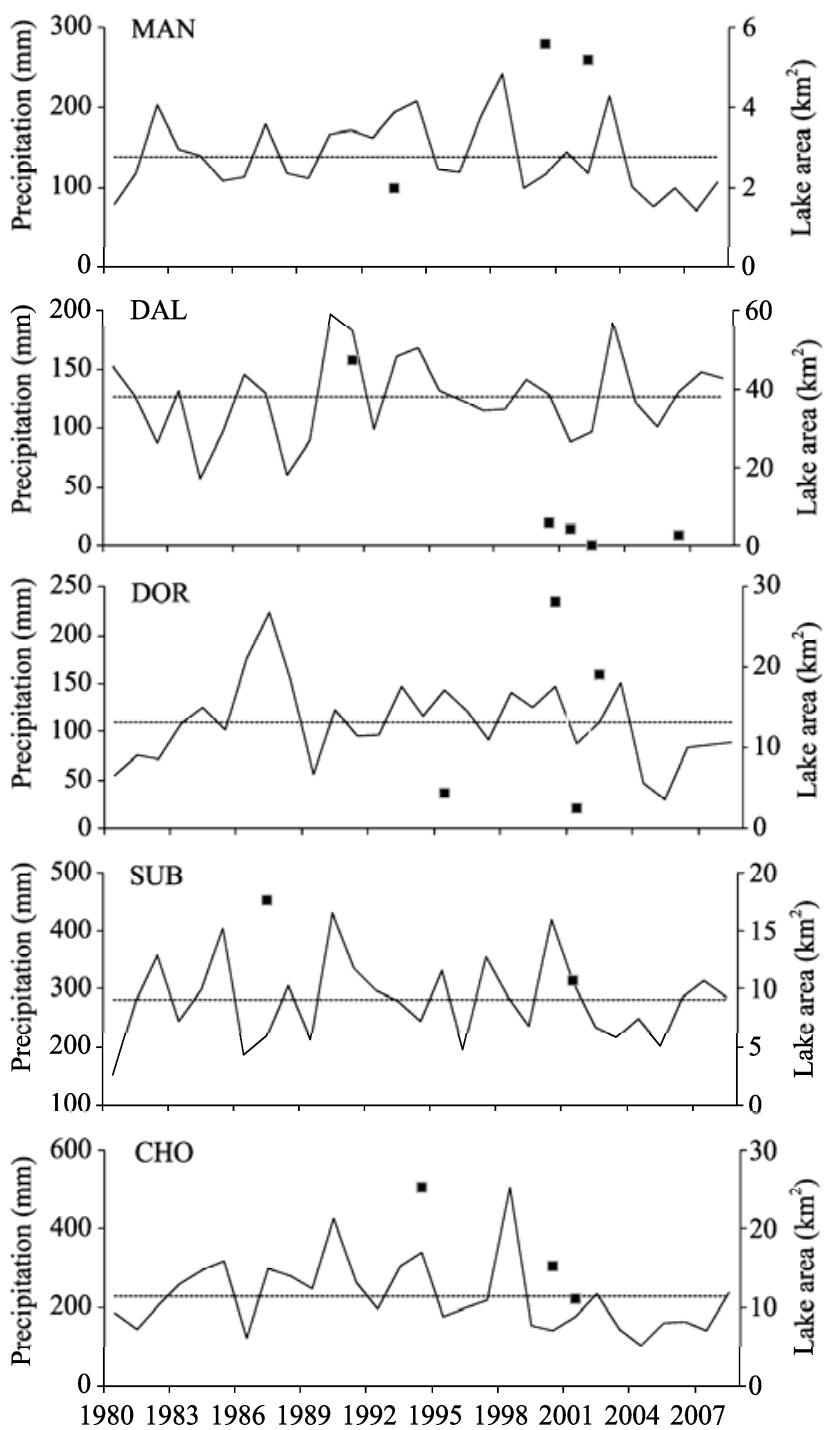

Fig. 3 Mean annual precipitation and lake area from 1980 to 2008 at the 10 study regions. The dotted lines and filled squares indicate the 29-year mean annual precipitation and total lake area in each sub-image estimated from the Landsat images, respectively. 


\subsection{Characteristics of regional lake area dynamics}

From the 10 study regions, a total of 165 lakes with areas greater than $10 \mathrm{hm}^{2}$ were identified. Most of the lakes were distributed in the central and eastern regions, while a few large lakes were in the west. The sub-image total lake area showed considerable variations across different regions and years (Table 1 and Fig. 3). The lake area was larger to the north of the Hanggai Range, compared to the south of the Hanggai Range and the eastern lowland regions. ULL had the largest lake area, over $3,500 \mathrm{~km}^{2}$, even though the region only contained two identified lakes.

Our results indicate that the temporal variation of lake area was considerable at each region, but the patterns of change were not similar across the study regions (Fig. 3). The temporal variations of lake area did not show simple monotonic patterns of increase or decrease. Some of the regions showed a generally decreasing pattern, which was the case for BUL, DAL, SUB and CHO. In contrast, lake area increased in the MAN region. ARV and DOR showed considerable fluctuations in lake area. In the case of ULL, ULI and MUR, the lake areas were similar across different years with absolute relative changes of $3.0 \%, 0.5 \%$ and $0.6 \%$, respectively.

The regionality of lake area change found in this study agrees with evidences from radar-altimetry lake level data that indicate distinct but spatially different inter-annual variations of lake level for inland lakes in the Central Asia regions for the last two decades. Big Aral Sea volume decreased consistently during the period of 1993-2005, while water level of Issykkul Lake (Kirgizstan) decreased in 1990s but increased again in 2000s (Cretaus and Birkett, 2006). Among four big lakes in the Mongolian Altai Range region, where their lake levels are regularly monitored with radar altimetry data (HYDROWEB, http://www.LEG OS.obs-mip.fr/soa/hydrologie/HYDROWEB; Cretaus et al., 2011), three lakes (i.e. Uvs, Hyargas and Har lakes) showed distinct drawdown in late 2000s. In contrast, the lake level of Har Us remained similar and even, and summer lake level increased in late 2000s.

It is noteworthy that DAL, in the south Gobi, showed the most dramatic decrease in lake area between 1991 and 2000 (Fig. 3). Over those 10 years, the lake area decreased over $80 \%$, from 47.1 to 5.9 $\mathrm{km}^{2}$. Most of the large lakes (over $6 \mathrm{~km}^{2}$ ) in $1991 \mathrm{had}$ disappeared by 2000. By 2002, all of the lakes had disappeared from this region, but 9 small lakes were detected again in 2006 (Table 1). The Ullaan Lake, once the largest lake in the Gobi, was identified in 1991 but did not appear in the Landsat images since 2000. The desiccated Ullaan Lake was identified as one of the dust storm hotspots in the Gobi region (Natsagdorj et al., 2003). In the $\mathrm{CHO}$ region of eastern Mongolia, the lake area in 2001 was only half of the area in 1994. In contrast, MAN showed an increase in lake area for a similar period, with the lake area $\left(5.6 \mathrm{~km}^{2}\right)$ in 2000 almost threefold larger than the area $\left(2.0 \mathrm{~km}^{2}\right)$ in 1993. DOR in southeastern Mongolia showed a greater fluctuation, from 2.6 to $28.1 \mathrm{~km}^{2}$ (Table 1).

Lake area change was accompanied by changes in the number of lakes. The Gobi lakes (i.e. ARV, MAN, DAL and DOR regions) showed frequent disappearance and reappearance (Table 1). On average, 17.3 lakes either disappeared or reappeared in the Gobi regions, compared with 2.3 lakes for the other regions. Our results on greater lake number changes in the Gobi regions are comparable with the high lake number change in Inner Mongolia and Xinjiang regions of China between 1960s-1980s and 2005-2006 (Ma et al., 2010). They interpreted the greater lake number change in the arid and sub-arid northern China primarily because of the evaporation increase induced by warming temperature and partly because of the agricultural activities in Xinjiang.

\subsection{Region-specific relationships between lake area and precipitation changes}

Our regression analysis shows different regional relationships between lake area and precipitation changes for ARV, DOR, DAL and BUL (Fig. 4). The lake area changes of ARV and DOR were explained well by precipitation changes at both monthly (M2, $R^{2}=0.92$ and $\left.\mathrm{M} 1, R^{2}=0.95\right)$ and annual $\left(\mathrm{Y} 1, R^{2}=0.81\right.$ and $\left.R^{2}=0.64\right)$ time scales, respectively. The results suggest a determinant role of precedent precipitation on lake area changes in ARV and DOR. The relationship between lake area and precipitation was less distinct for the BUL-region lakes. Y1 precipitation accounted for 
$45 \%$ of the lake area change $(P<0.05)$, which was higher than that $\left(R^{2}=0.34, P=0.077\right)$ of monthly precipitation (M2). For the DAL region, the lake area change was poorly correlated with precipitation changes at both monthly and annual time scales (M1, $R^{2}=0.26$ and Y0, $R^{2}=0.028, P>0.05$ ), respectively. When the data from year 1991 was excluded, the M1
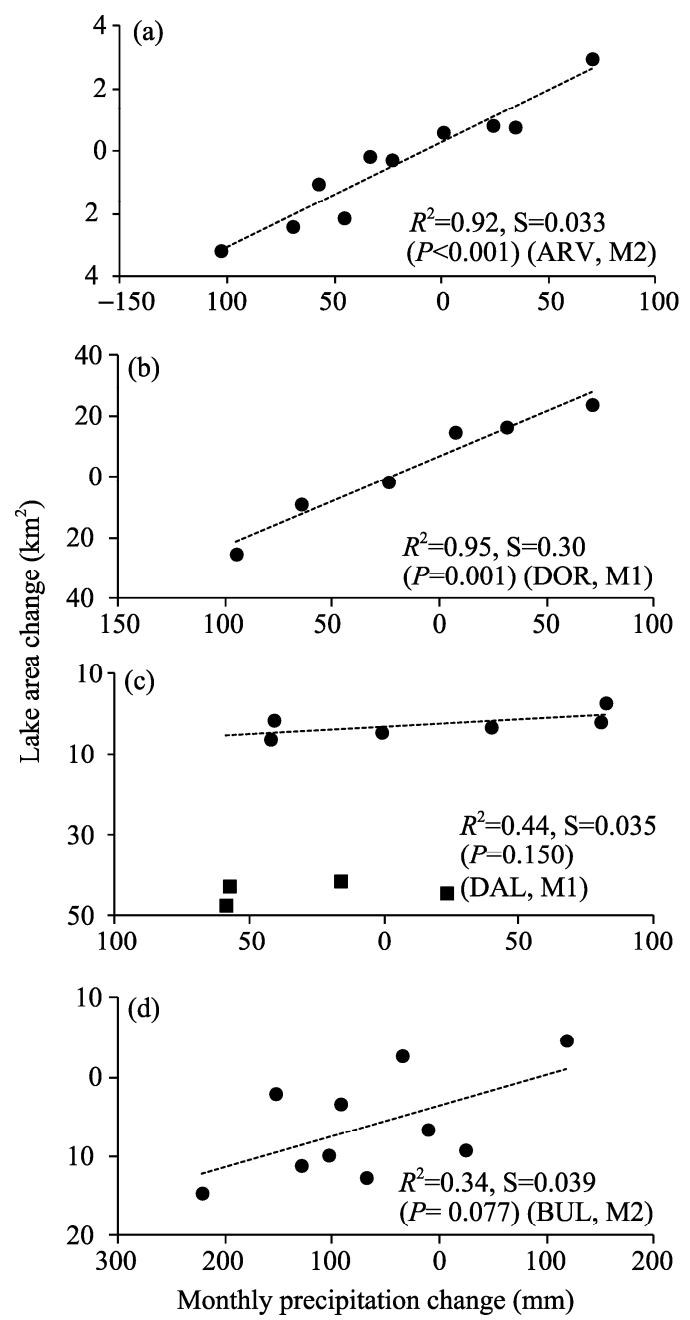

and $\mathrm{Y} 0$ precipitation changes explained the lake area change slightly better by up to $44 \%(P=0.15)$ and $40 \%$ ( $P=0.18)$, respectively. On the other hand, among the statistically meaningful regressions, DOR showed much higher sensitivity of lake area to precipitation change (i.e. slope, $\left.\mathrm{S}=0.30 \mathrm{~km}^{2} / \mathrm{mm}\right)$ than ARV $(0.033$ $\left.\mathrm{km}^{2} / \mathrm{mm}\right)$ and BUL $\left(0.047 \mathrm{~km}^{2} / \mathrm{mm}\right)$.
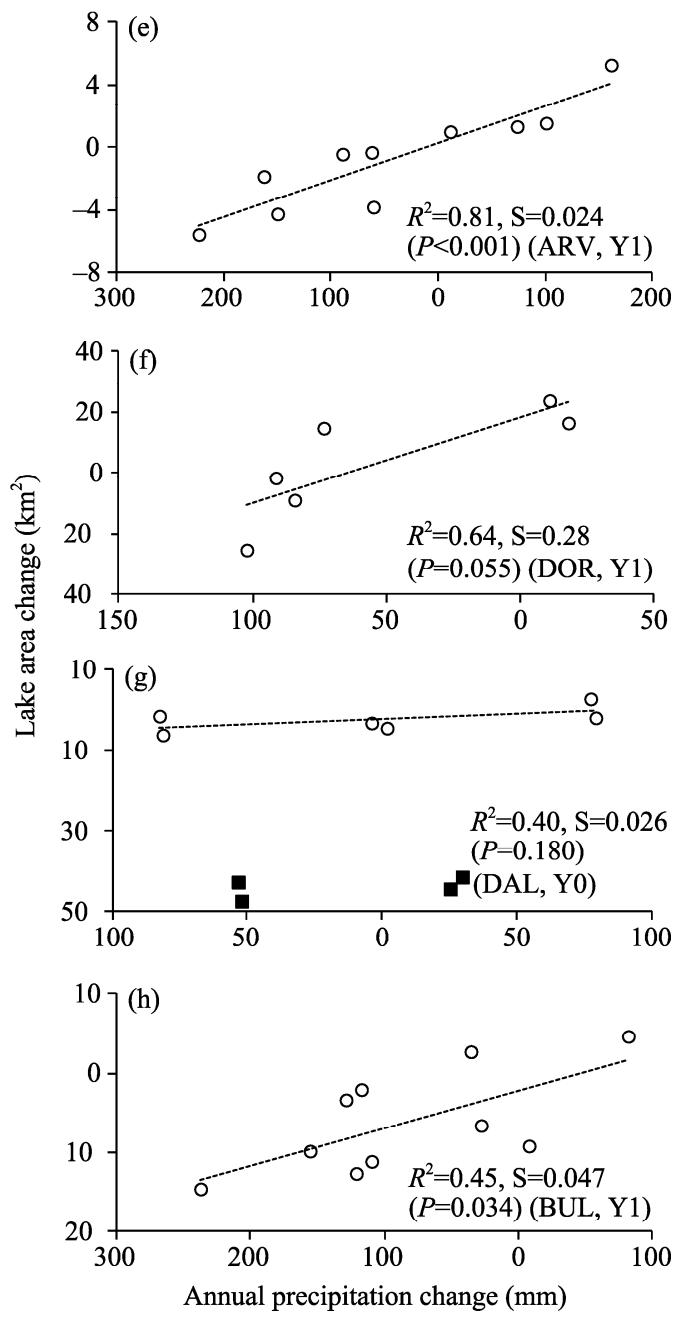

Fig. 4 Relations of lake area change with annual (left) and monthly (right) precipitation change. Y1, M1 and M2 indicate precedent periods of annual $(\mathrm{Y})$ and monthly $(\mathrm{M})$ precipitation (i.e. one and two years or months ago, respectively) used for the regression analysis. The $R^{2}, \mathrm{~S}$ and $P$ are the coefficient of determination, slope of regression and significant level, respectively. The filled squares in the DAL region indicate values derived from the lake area data in 1991 that were not used in the regression analysis of that region.

We interpret the regional difference of regression analyses in terms of different regional climate and hydromorphological characteristics. The four study regions show good gradients of temperature and precipitation for the period of 1980-2008 (Fig. 2). DOR and DAL are very hot-and-dry regions (AMT and
MAP, $4.8^{\circ} \mathrm{C}$ and $126 \mathrm{~mm}$ ), compared with medium level and cold-and-wet climates of $\mathrm{ARV}\left(1.5^{\circ} \mathrm{C}\right.$ and $227 \mathrm{~mm})$ and BUL $\left(-0.6^{\circ} \mathrm{C}\right.$ and $\left.329 \mathrm{~mm}\right)$, respectively. In all regions, more than two-third annual precipitation $(70 \% \pm 0.05 \%)$ falls during June-August. Mean June-to-August air temperature was significantly 
cooler in BUL $\left(15.3 \pm 1.2^{\circ} \mathrm{C}\right)$ than in the other regions $\left(21.0 \pm 1.3^{\circ} \mathrm{C}\right)(P<0.05)$. Though the freezing months were from November to March for the regions, BUL showed distinctly colder April $\left(2.1^{\circ} \mathrm{C}\right)$ and October $\left(0.77^{\circ} \mathrm{C}\right)$ than the other regions $\left(6.9^{\circ} \mathrm{C}\right.$ and $5.2^{\circ} \mathrm{C}$, respectively) $(P<0.05)$, which suggests longer snow and freezing seasons of BUL.

The four study regions also showed good contrasts in basin and lake hydromorphology. BUL is located in the middle of the Selenge River that contains large drainage area in high mountainous regions. As well, most of the BUL-region lakes were found along or nearby river channels. In contrast, small terminal lakes constitute most of the lakes found in ARV, DOR and DAL. The three regions showed consistently smaller mean lake areas of $0.37,0.75$ and $1.0 \mathrm{~km}^{2}$, respectively, compared with that $\left(1.7 \mathrm{~km}^{2}\right)$ of BUL. The mean lake size of DAL was $0.51 \mathrm{~km}^{2}$, except for the Ullaan Lake. Across the ARV and DAL regions, the Ongi River flows from the Hanggai Range to the Ullaan Lake but this river has much smaller drainage area and discharge rate than the Selenge River.

Our investigation on regional climate and hydromorphological characteristics suggests that the lake areas of the hot-and-dry ARV, DAL and DOR regions may vary subtly with seasonal hydrological imbalance between precipitation and evapotranspiration in the small isolated lake basins. Because of the small lake size and consistently high atmospheric water demand (i.e. potential evapotranspiration) of those regions, the lake area change should be closely related with temporal precipitation variability. Whereas, for the BUL region, seasonal and inter-annual variations of the Selenge River discharge rate could play a critical role in determining water bodies stored in the riverside lakes. This suggests that more complex hydrology is concerned in the BUL-region lakes, which includes multi-seasonal snow and frozen soil-layer dynamics in the large mountainous basin area and also occurrence of river flooding to the riverside lakes. Similarly, Ma et al. (2010) illustrated the importance of seasonal snow dynamics on surface water area of Siling Co, the largest salt water lake in Tibet at present.

It seems that our inferences generally agree with the results of the regression analyses, except those from the DAL region. Linear relationships between lake area and precipitation change were stronger in ARV and DOR than in BUL. As well, regional climatic regimes explained the regional difference of the precipitation memory length $\left(l_{m}\right)$. For the cold-and-wet BUL and the other hot-and-dry regions, annual and monthly precipitation better accounted for the lake area change, respectively. Within the hot-and-dry climatic regime, more hot-and-dry DOR and DAL regions $\left(4.8^{\circ} \mathrm{C}\right.$ and $\left.116 \mathrm{~mm}\right)$ showed shorter monthly $l_{m}$ (M1) than the less hot-and-dry ARV region $\left(1.5^{\circ} \mathrm{C}\right.$ and $\left.227 \mathrm{~mm}\right)$.

In spite of hot-and-dry climate regime of DAL similar to ARV and DOR, poor regressions were found in DAL at both monthly and annual scales. The poor correlations were primarily due to the massive lake area reduction that occurred after 1991 (Fig. 3), which appeared as asterisks in Fig. 4. The massive lake reduction was mostly explained by the disappearance of the Ullaan Lake, a terminal lake of the Ongi River originated from the Hanggai Range. This suggests the important roles of river dynamics in determining the lake area change in DAL for the study period, which is compared with the prevalent roles of small-basin vertical water balance between precipitation and evapotranspiration for the DOR and ARV regions.

\subsection{Cross-regional relation between changes in lake area and precipitation}

The specific lake area change $\left(\overline{A_{\text {lake }}^{j k}}\right)$ was plotted against the monthly and annual precipitation changes to examine cross-regional patterns of lake area change with respect to monthly and annual precipitation changes. The best monthly and annual memory lengths found in this regression analyses were precedent two months (M2) and current year (Y0), respectively. The spatial and temporal patterns of specific lake area change were fairly well accounted for by precipitation change across the study regions. At most of the regions, except ULL, DOR and DAL, both M2 and $\mathrm{Y} 0$ precipitation changes accounted for $47 \%$ of the variability in specific lake area change (Fig. 5). As illustrated in Fig. 4, our analysis on the specific lake area change also indicates that the lake area change associated with the massive lake reduction in DAL (i.e. four asterisks in Fig. 5) was not accountable with the precipitation change. 

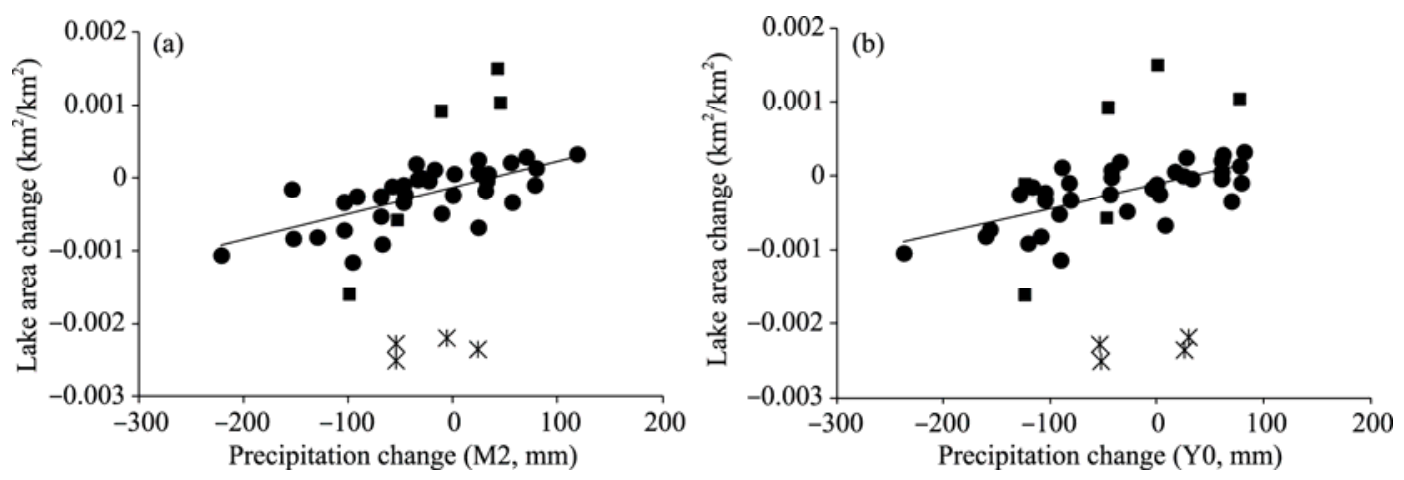

Fig. 5 Relations of specific lake area change with (a) monthly and (b) annual accumulated precipitation change. Data from ULL region were not shown because the specific lake area change value was too large. The filled squares are data from DOR. The asterisks indicate data from DAL based on lake area data from 1991 Landsat images.

Although precipitation change was still a good indicator of the specific lake area change in DOR for the M2 $\left(R^{2}=0.90, P=0.004\right)$ and Y0 $\left(R^{2}=0.54, P=0.096\right)$ precipitation memory, the respective slopes of the specific lake area change were more than 3 times steeper $\left(\mathrm{S}=20\right.$ and $\left.10 \mathrm{~m}^{2} / \mathrm{mm}\right)$ than those of the other regions ( $\mathrm{S}=4$ and $3 \mathrm{~m}^{2} / \mathrm{mm}$ ) at both monthly and annual scales. It is uncertain why the specific lake area change was more sensitive to precipitation changes in DOR than in the other regions. We propose two possible reasons, although testing these hypotheses remains for future research. First, the small and shallow lake morphology could result in higher sensitivity. The other possible cause is the effect of the severe drought conditions found in this region since the late 1990s. The DOR region has been subject to severe droughts and consequent land degradation, with an increased occurrence of sand-storms in the early 2000s (Kim, 2008; Igarash et al., 2009). This abnormal drought condition might draw down groundwater level substantially, so to increase the vulnerability of lake area change, i.e. rapid lake depletion.

It was notable that the ULL region, in contrast to the other regions, showed significant negative $(R=$ -0.99, $P=0.018, n=3$; not shown in Fig. 4) correlation of lake area change with annual precipitation. It seems hard to explain the negative correlation in the scope of this study. The ULL region contains the Uvs Lake, the largest lake (about 3,500 $\mathrm{km}^{2}$ ) in Mongolia, surrounded by high northern mountains and seasonal permafrost area. Erdentuya et al. (2006) reported good positive relationships between observed the water lev- el of the Uvs Lake, 5-a moving average of tree ring width, and the retreat of surrounding glaciers. Hence, the lake hydrology of this region might be more complex than those of other lakes, since additional considerations of warming effect on glacier and permafrost layer dynamics are required as reported for Tibetan lakes of China (Liu et al., 2009) and Issyk-Kul Lake of Kyrgyzstan (Romanovsky et al., 2013).

\section{Conclusions}

Multi-temporal satellite detection of lake areas enabled us to examine the variability of lake area change and its relation with precipitation change in Mongolia. The temporal variation of lake area was considerable at each region, but the patterns of change varied across all study regions (Fig. 3). The temporal lake area variability was larger in the Gobi regions, where densely distributed small lakes prevail. Lake disappearance and reappearance also showed more variation in the dry Gobi regions (Table 1).

Our study indicates that the observed lake area change was primarily related to the precedent precipitation change in many of the regions of Mongolia investigated in this study but also suggests the importance of regional climate regime and hydromorphological characteristics on the relationships between lake area and precipitation changes (Figs. 4 and 5). Generally, the lake area change in the Gobi regions showed higher correlations with precipitation change. Our regression analyses enabled us to identify some potential regions where factors other than precipitation might play important roles in determining the lake 
area change. For example, the massive lake disappearance in DAL was not well explained by precipitation changes alone (Fig. 5). Development of riverside lakes requires careful investigations on multi-seasonal river dynamics in BUL. As well, the negative annual correlation found in ULL implicates the importance of other hydrological processes in determining the lake area change of such a big lake surrounded by high mountains. The higher sensitivity of lake area change to precipitation found in DOR needs more investigation. To understand the cause-and-effect relations of lake area change for such lakes, more comprehensive hydrological research is necessary in future studies.

This study is confined to the evaluation of the roles of precedent precipitation change in determining lake area change between certain time intervals. It did not explain how lake area is determined and related with precipitation. Those questions require more considerations on various hydrological processes associated with lake-basin hydrology at appropriate temporal scales for investigating seasonal lake area change. In spite of the limitations, we consider that our study provides new information to understand regional characteristics of precipitation-driven lake area change across different regions of Mongolia.

\section{Acknowledgements}

This work was supported by research grants from Korea Forest Service (S211212L06301) and from National Research Foundation of Korea (NRF-2013R1A1A4A01008632). Sinkyu KANG was partly supported by Kangwon National University (C1009843-01-01). We greatly appreciate Altanbagana for collecting the meteorological data.

\section{References}

Batima P, Natsagdorj L, Gombluudev P, et al. 2005. Observed climate change in Mongolia. AIACC Working Paper, 12: 5-20.

Castaneda C, Herrero J, Casterad, M A. 2005. Landsat monitoring of paya-lakes in the Spanish Monegros desert. Journal of Arid Environments, 63: 497-516.

Chavez P S Jr. 1996. Image-based atmospheric corrections-revisited and improved. Photogrammetric Engineering and Remote Sensing, 62(9): 1025-1036.

Chuluun T, Altanbagana M, Tserenchunt B. 2010. Land degradation and desertification in Mongolia. Background paper for Mongolian Human Development Report, Ulaanbaatar, Mongolia.

Cretaus J F, Birkett C. 2006. Lake studies from satellite radar altimetry. Comptes Rendus Geoscience, 338: 1098-1112.
Cretaus J F, Jelinski W, Calmant S, et al. 2011. SOLS: A lake database to monitor in the Near Real Time water level and storage variations from remote sensing data. Advances in Space Research, 47: 1497-1507.

Davaa G, Mijiddory R, Khudulmur S, et al. 2005. Responses of the Uvs lake regim to the air temperature fluxtuations and the environment changes. In: Proceedings of the Fist International Symposium on Terrestrial and Climate Change in Mongolia. Ulaanbaatar, Mongolia, 130-133.

Davaa G, Oyunbaatar D, Sugita M. 2006. Surface water of Mongolia. In: Environmental Book of Mongolia. Tokyo, Japan, 55-82.

Dietz A J, Amgalan E, Erdenechuluun T, et al. 2005. Carrying capacity dynamics, livestock commercialization and land degradation in Mongolia's free market era. Poverty Reduction and Environmental Studies, Vrije University, the Netherlands.

Erdenetuya M, Khishigsuren P, Davaa G, et al. 2006. Glacier change estimation using Landsat TM data. International Archives of the Photogrammetry, Remote Sensing and Spatial Information Science, 36, Part 6, Tokyo.

Igarash Y, Inomata Y, Aoyama M, et al. 2009. Possible change in Asian dust source suggested by atmospheric anthropogenic radionuclides during the 2000s. Atmospheric Environment, 43: 2971-2980.

Johnson D A, Sheehy D P, Miller D, et al. 2006. Mongolian rangelands in transition. Secheresse, 17: 133-141.

Kawata Y, Ohtani A, Kusaka T, et al. 1990. Classification accuracy for the MOS-1 MESSR data before and after the atmospheric correction. IEEE Transactions. Geoscience and Remote Sensing, 28: 755-760.

Kim J. 2008. Transport routes and source regions of Asian dust observed in Korea during the past 40 years (1965-2004). Atmospheric Environment, 42: 4778-4789.

Komatsu G, Brantingham P J, Olsen J W, et al. 2001. Paleoshoreline geomorphology of Boon Tsagaan Nuur, Tsagaan Nuur and Orog Nuur: the Valley of Lakes, Mongolia. Geomorphology, 39: 83-98.

Lillesand T M, Kiefer R W, Chipman J W. 2004. Remote sensing and image interpretation, $5^{\text {th }}$ edition. USA, John Willey \& Sons, 574-575.

Liu H J, Zhou C H, Cheng W M, et al. 2008. Monitoring sandy desertification of Otindag Sandy Land based on multi-date remote sensing images. Acta Ecologica Sinica, 28(2): 627-635.

Liu J, Wang S, Shumei Y, et al. 2009. Climate warming and growth of high-elevation inland lakes on the Tibetan Plateau. Global and Planetary Change, 67: 209-217.

Ma R H, Duan H T, Hu C M, et al. 2010. A half-century of changes in China's lakes: global warming or human influence? Geophysical Research Letters, 37: L24160, doi: 10.1029/2010GL045514.

Nadintsetseg B, Shinoda M. 2011. Seasonal change of soil moisture in Mongolia: its climatology and modeling. International Journal of Climatology, 31: 1143-1152.

Nakayama Y, Yanagi T, Yamaguchi S, et al. 2007. Monitoring of environmental change in Dzungar Basin by the analysis of multi-temporal satellite data sets. Advances in Space Research, 39: 52-59.

Natsagdorj L, Jugder D, Chung Y S. 2003. Analysis of dust storms observed in Mongolia during 1937-1999. Atmospheric Environment, 37: 1401-1411. 
Neupert R F. 1996. Population, nomadic pastoralism and the environment in the Mongolian Plateau. Population and Environment, 20: 413-441.

Romanovsky V V, Tashbaeva S, Crétaux J F. 2013. The closed Lake Issyk-Kul as an indicator of global warming in Tien-Shan. Natural Science, 5(5): 608-623.

Saizen I, Maekawa A, Yamamura N. 2010. Spatial analysis of time-series changes in livestock distribution by detection of local spatial associations in Mongolia. Applied Geography, 30: 639-649.

Scepan J, Menz G, Hansen M C. 1999. The DISCover validation image interpretation process. Photogrammetric Engineering and Remote Sensing, 65: 1075-1081.
Song C, Woodcock C E, Seto K C, et al. 2001. Classification and change detection using TM data: when and how to correct atmospheric effects? Remote Sensing of Environment, 75: 230-244.

Tsujimura M, Abe Y, Tanaka T, et al. 2007. Stable isotopic and geochemical characteristics of groundwater in Kherlen River basin, a semi-arid region in eastern Mongolia. Journal of Hydrology, 333: 47-57.

UNEP RRC.AP. 2002. State of environment, Mongolia 2002. AIT-UNEP Regional Resource Centre for Asia and Pacific. http://www.rrcap.unep.org/pub/soe/mongoliasoe.cfm.

Yang H, Lee E, Do N, et al. 2012. Seasonal inter-annual variations of lake surface area of Orog Lake in Gobi, Mongolia during 2000-2010. Korean Journal of Remote Sensing, 28: 267-276. 